\title{
Violência contra a mulher no território da 25a Agência de Desenvolvimento Regional (ADR) catarinense: realidade social, políticas públicas e implicações para o desenvolvimento
}

Jaqueline Fátima Previatti ${ }^{1}$ Maria Luiza Milani²

\section{Resumo}

O estudo refere-se à violência contra a mulher no território da 25a Agência de Desenvolvimento Regional (ADR) catarinense, descrevendo a realidade social, as políticas públicas e suas implicações para o desenvolvimento dessa região. O desenvolvimento do estudo processou uma pesquisa bibliográfica e diagnóstica, nos municípios de Mafra, São Bento do Sul, Rio Negrinho, Campo Alegre, Itaiópolis, Papanduva e Monte Castelo, onde foram pesquisados 3769 Boletins de Ocorrência (BO) com registros de violência contra as mulheres, entre 2009 a 2012, em cinco delegacias de polícia civil e duas delegacias de proteção à criança, adolescente, mulher e idoso. Com o objetivo de estudar o cenário, na 25a ADR, da violência contra as mulheres e as implicações no processo de desenvolvimento, tem-se como resultados que, em municípios onde há rede de atenção ao atendimento às mulheres, o número de denúncias aumentou. Também fica evidente a presença da violência na região, havendo, pois, comprometimento ao bem-estar e interferências nos processos para o desenvolvimento regional. A violência doméstica, quando os conflitos familiares e sociais promovem riscos e vulnerabilidades, interfere no bem-estar social. Mas as políticas públicas para o enfrentamento da violência contra as mulheres se ampliaram, intensificando as perspectivas de enfrentamento desse dilema social que interfere individual e coletivamente nas sociedades. Os aspectos preocupantes que a pesquisa apontou referem-se ao seu desconhecimento pelos setores e instituições sociais. Se as políticas públicas não estão efetivamente sendo implantadas pelas mais variadas questões, comprometem-se as expectativas do desenvolvimento humano, social e regional.

Palavras-chave: Violência contra a mulher. Cenário regional. Políticas públicas. Desenvolvimento Regional.

\footnotetext{
${ }^{1}$ Mestre em Desenvolvimento Regional pela Universidade do Contestado (UnC). Secretária Municipal de Saúde de Mafra (SC). paulo_jaque@brturbo.com.br

${ }^{2}$ Doutora em Serviço Social: Serviço Social, Políticas Sociais e Movimentos Sociais. Docente da Universidade do Contestado (UnC), Programa de Mestrado em Desenvolvimento Regional. Canoinhas (SC).marialuiza@unc.br
} 


\begin{abstract}
The study refers to the scenario of violence against women in the territory of the 25th Regional Development Agency (ADR) of Santa Catarina, as well as indicate the implications to the development of this region. The development of study sued the bibliographical research and Diagnostics, in the municipality of Mafra, São Bento do Sul, Rio Negrinho, Campo Alegre, Itaiópolis, Papanduva and Monte Castelo, where they were searched 3769 Police Occurrences (PO) with records of violence against women, between 2009 to 2012, in five Civil Police stations and two police stations child, teenager, Woman and Elderly. With the objective of studying the scene of the violence that women in the 25th ADR and implications in the development process, as results that in the municipalities where there is network of attention to women the numbers of complaints increased. It is also evident the presence of violence in the region, soon there's compromises with the welfare and interference in the processes for the development regional. Domestic violence is a likely interference on welfare when the family conflicts and promote social risks and vulnerabilities. But the public policies for combating violence against women if broadened and intensified the prospects of tackling this social dilemma that interferes with individually and collectively in society. Aspects of concern that research pointed refers to his ignorance by sectors and social institutions. If public policies are not effectively being deployed by various issues, undertakes the expectations of human, social and regional development.
\end{abstract}

Keywords: Violence against women. Regional scenario. Public policies. Regional Development.

\title{
1 Introdução
}

O tema deste estudo aborda o fenômeno da violência de gênero praticada contra as mulheres residentes no território da 25a Agência de Desenvolvimento Regional (ADR), no Estado de Santa Catarina, bem como descreve a realidade social, as políticas públicas e suas implicações para o desenvolvimento dessa região.

O objeto de estudo emergiu da vivência profissional da pesquisadora na Unidade de Pronto Atendimento de Mafra, local para onde as mulheres vítimas de atos violentos são encaminhadas para atendimento de emergência. Em determinados atendimentos, essas mulheres vítimas de violência não sobreviveram devido à agressão sofrida. Quando sobrevivem, não encontram uma sequência no atendimento que possa apoiá-las. Há um ônus social e econômico decorrente desse processo: a violência fazendo vítimas, as políticas públicas demandando mais recursos e investimentos; as famílias destroçadas e a vulnerabilidade das relações sociais, colocando em risco o bem-estar e as dimensões do desenvolvimento. Para tanto, diante dessas lacunas percebidas pela pesquisadora quanto aos diversos âmbitos do atendimento às mulheres vítimas da violência, emergem as inquietudes que estimularam o desenvolvimento deste estudo, para que se produzisse um viés desse cenário a fim de fundamentar análises e discussão do problema no território estudado.

Para o desenvolvimento dos estudos e da pesquisa de campo, utilizamos, 
como base referencial, as políticas públicas para enfrentamento da violência contra as mulheres, as quais apresentam, em seu conteúdo, conceitos, diretrizes definidas, normas e estratégias para as ações, objetivando fortalecer e estruturar a atenção às mulheres, garantindo-Ihes o direito à saúde, à igualdade e à vida, expressos na Constituição Federativa do Brasil de 1988, como também a base referencial do desenvolvimento em suas dimensões humanas e sociais, no intuito de agregar elementos para a superação do custo econômico da violência.

Durante a construção da política pública de proteção às mulheres no Brasil, vêm sendo constituídos dispositivos para estabelecer o respeito aos direitos e deveres dos sujeitos. Dessa forma, as leis são submetidas aos fatos, e nem sempre se considera o direito à vida dos membros de uma comunidade social e política, ficando obscura a individualidade dos grupos sociais e as dinâmicas territoriais onde se situam.

Diversas são as mobilizações e discussões para dar conta da problemática da violência contra as mulheres no Brasil e mundialmente. As conferências realizadas no século $X X$, as quais discutem os direitos humanos para os habitantes do mundo, contribuíram para a detecção e investigação da violência de gênero contra a mulher, percebida, em ordem temporal, nos seguintes documentos: Carta das Nações Unidas (1945); Convenção contra o Genocídio (1948), Pacto Internacional dos Direitos Civis e Políticos (1966); Pacto Internacional dos Direitos Econômicos, Sociais e Culturais (1966); Convenção sobre a eliminação de todas as formas de discriminação racial (1965); Convenção para a eliminação de todas as formas de discriminação contra a mulher (1979); Convenção contra a tortura e outros tratamentos ou penas cruéis, desumanas ou degradantes (1984); Convenção sobre os direitos da criança (1989) e Convenção interamericana para prevenir, punir e erradicar a violência contra a mulher, em convenção em Belém do Pará, em 1994. Dessas discussões, emergiram a legislação nacional vigente, a Constituição Federal do Brasil (BRASIL, 1988) e acordos internacionais, leis que garantissem, na atualidade, os direitos das mulheres a uma vida sem violência.

No Brasil, o marco visível do enfrentamento da problemática relacionada à violência contra a mulher deu-se no final dos anos 1970, quando foram instituídos os grupos SOS Mulheres. Nesses grupos, havia representantes de variados grupos feministas, aliados a grupos políticos de distintas correntes ideológicas. Em 1985, foram criadas as Delegacias Especiais de Atendimentos às Mulheres (DEAMs), por meio do Decreto no 2170, de 24 de outubro de 1985, resultante de pressões exercidas pelos movimentos sociais. Nessa perspectiva, Suárez e Bandeira (2002) evidenciam que as delegacias se constituíram nas primeiras respostas institucionais colocadas à disposição das mulheres no enfretamento da problemática da violência contra elas. Ou seja, a ampliação institucional para conter o abuso ao direito humano à vida.

Essas instituições foram concebidas com o objetivo de atender a uma clientela específica: as mulheres em situação de violência, especialmente a violência doméstica. Logo, o custo econômico das delegacias pode ter sido o fator que influenciou, em primeira linha, a sua implementação e manutenção. Depois de 20 anos desse decreto, o que efetivamente mudou nesse cenário? Como as demais intervenções, conjugadas para o desenvolvimento humano, social e dos territórios, estão proces- 
sando o bem-estar e a dignidade humana?

Sob essas questões de fundo analítico-conjuntural, nacional e internacional, o cenário das violências a que as mulheres são submetidas no território dos municípios componentes da 25a ADR, em especial entre 2009 a 2012, torna-se o escopo do estudo ora apresentado. Parte do estudo voltou-se também para a identificação e descrição da dinâmica das políticas públicas operacionalizadas no território de modo a responder a esse enfrentamento.

Diante dessas questões, o objetivo do estudo foca-se em evidenciar o cenário da violência contra as mulheres no território da 25a Agência de Desenvolvimento Regional, no período de 2009 a 2012, e suas prováveis implicações no processo de desenvolvimento regional.

A justificativa do estudo e pesquisa recaiu sobre o escopo estratégico das políticas públicas para o enfrentamento dos dilemas da sociedade, bem como da violência contra as mulheres, mas visam, sobretudo, contemplar a amplitude das necessidades humanas e sociais para o desenvolvimento.

Acrescentaram-se a esses aspectos justificadores do estudo, as problemáticas econômicas e sociais em torno de gênero, agravadas para as mulheres. $O$ ato da violência desencadeia um processo abrangente e complexo sobre o qual as instituições e setores da sociedade envolvidos não têm domínio ou não asseguram o direito à vida e ao bem-estar. Portanto, o impulso para a elaboração do estudo parte a priori da constatação da fragilidade do processo de implantação do Pacto pelo Enfrentamento à Violência contra as Mulheres (BRASIL, 2011a), bem como do desconhecimento das características e das formas de violência às quais as mulheres da 25a ADR estão sendo submetidas. Os profissionais desconhecem a rede de atenção a essas mulheres. Se há desconhecimentos quanto à operacionalização das políticas públicas e como fortalecê-las para o desenvolvimento humano, social, regional, devendo ela agregar múltiplas áreas, tais como saúde, educação, assistência social e segurança, numa simbiose institucional comprometida com o desenvolvimento, só se pode concluir, realmente, pela fragilidade desse processo.

A pesquisa desenvolvida utilizou procedimentos diversificados, conforme temas e etapas. Além da pesquisa bibliográfica, que fundamentou o referencial teórico, o estudo diagnóstico orientou a pesquisa de campo, realizada em instituições de segurança pública como Delegacias de Polícia Civil e Delegacias de Proteção a Crianças, Adolescentes, Mulher e Idoso (DPCAMI) na 25a ADR. Nessas instituições - e pela pesquisa diagnóstica - foram estudados documentos denominados Boletim de Ocorrência (BO). Ao todo foram 3.769 BOs, registrados durante o período de 2009 a 2012, com fato denunciado explícito de violência contra a mulher. Os registros de violência contra as mulheres consultados nos BOs das delegacias referiram-se aos municípios de Mafra, São Bento do Sul, Rio Negrinho, Campo Alegre, Itaiópolis, Papanduva e Monte Castelo, numa região denominada de 25a ADR.

Considerou-se o registro de violência contra a mulher da faixa etária dos 18 anos aos 59 anos de idade. Os dados quantitativos coletados foram codificados, tabulados e analisados sob a orientação dos teóricos consultados.

O texto apresentado caracteriza violência e violências, depois evidencia o seu 
enfretamento pelas políticas públicas, para, em seguida, evidenciar o cenário da violência de gênero - contra a mulher - na 25a ADR, finalizando com as reflexões finais, as implicações sobre o desenvolvimento.

\section{Violência(s)}

Violência significa força; portanto, constrangimento, dominação por meio da força física sobre o outro. A violência é tema amplamente discutido nas sociedades, de complexa e difícil definição teórica.

A violência sofre influências culturais e modificações com o desenvolvimento dos valores sociais e das normas convencionais. O fenômeno da violência sofre mutações na história da humanidade e nos espaços. A violência é uma manifestação humana que, segundo Minayo (2006), decorre de ações realizadas por indivíduos, classes, nações, ou por omissões dessas mesmas instâncias. Dos seus atos, geram-se danos físicos, emocionais, morais a si e aos outros, enraizados nas estruturas sociais e políticas bem como na consciência dos indivíduos.

A violência apresenta-se de forma complexa e multifacetada, e, em relação ao gênero, segundo Morgado (2008), não é um fenômeno recente. Está presente em todas as classes sociais e sociedade, compondo-se de um conjunto de relações sociais, tomado de complexa compreensão. Dessa forma, diante da violência de gênero, podemos inferir que se trada de um fenômeno de natureza social, produto de um conjunto de determinantes que derivam da convivência dos grupos e da estruturação das sociedades.

Segundo Alberdi et al. (2002), para que possamos entender a denominação de violência de gênero, devemos levar em conta a condição de homens e mulheres na sociedade e o caráter social dos traços atribuídos para ambos. Na constituição do modelo familiar tradicional, as mulheres assumiram papéis diferenciados dos homens. Então, as condições de gênero atribuídas aos diferentes sexos, tradicionalmente, legitimaram a dominação do homem sobre a mulher, o que, nas sociedades recentes, vem sendo contestado.

De acordo com o II Plano Nacional de Políticas para as Mulheres (BRASIL, 2008), as denominações violência doméstica e violência familiar estão respaldadas pela Lei Maria da Penha (BRASIL, 2006), no seu Art. 5ㅇ; a violência conjugal é aquela que se dá em qualquer relação íntima de afeto, na qual o agressor permanece convivendo ou conviveu com a ofendida, independentemente de coabitação. Já a violência contra a mulher é qualquer ato de violência de gênero que resulte em qualquer ação física, sexual ou psicológica, incluindo a ameaça.

No que tange ao significado da violência e todas as consequências que surgem da ocorrência deste fenômeno, na sociedade patriarcal em que vivemos, existe uma forte banalização da violência de forma que há uma tolerância e até certo incentivo da sociedade para que os homens possam exercer sua virilidade baseada na força/dominação com fulcro na organização social de gênero. Dessa forma, é 'normal e natural que os homens maltratem suas mulheres, assim como que pais e mães maltratem seus filhos, ratificando, deste modo, a pedagogia da violência' (SAFFIOTTI, 2004, p. 74). 
A violência nega valores tais como liberdade, igualdade e a própria vida, reduzindo o exercício da cidadania de quem a ela é submetida e, principalmente, o gozo da liberdade. A violência é também uma ameaça permanente à vida dos seres humanos, por constituir-se em constante alusão à morte, pela magnitude dos atos, pela crueldade do agressor e pela passividade e silêncio do agredido. Cabe ressaltar que os dados expostos se devem às condições oferecidas para as mulheres na sociedade brasileira. Segundo destaca a ONU (OPAS, 2007), as meninas estão em melhores condições educacionais que os meninos, elas permanecem mais tempo nas escolas e concluem o ensino.

Para tanto, a violência doméstica faz-se para além da dominação de força exercida pelo homem, sofre forte influência de fatores externos, denominados por vulnerabilidades sociais, que contribuem para a elevação de seus índices. Dessa forma, o conceito de vulnerabilidade social denota as situações intermediárias que afetam determinado grupo de pessoas. Para tanto, o termo vulnerabilidade adquire, com o tempo, papel de destaque na análise das condições sociais da população como parte deste campo conceitual, impulsionado pela crise social, desagregação dos trabalhadores formais, ascendendo o processo de exclusão social e evidenciando novo rumo para os estudos deste tema. Diante das várias nuances discretas do tema exclusão social, percebemos que essas situações intermediárias dizem respeito às condições de desigualdade e mobilidade a que determinados grupos sociais estão sujeitos.

Dessa forma, a vulnerabilidade social, no mundo da violência ao gênero feminino, é ressaltada pela amplitude desse conceito no entendimento dos eventos que vulneralizam as pessoas, não somente por determinantes de natureza econômica, mas considerados também fatores como a fragilização dos vínculos afetivos, as discriminações sociais e seu vínculo com a violência, as relações territoriais e políticas, dentre outros, situações estas que afetam as pessoas. As situações de vulnerabilidade são geradas pela sociedade e podem ser originárias da forma como as pessoas lidam com as perdas, os conflitos, a morte, a separação, as rupturas, as questões materiais e, em especial, as relações de poder.

Segundo Minayo e Souza (1999), no Brasil, o tema insere-se na agenda da Saúde Pública, principalmente a partir da década de 1980, mas com mais ênfase nos anos 1990, pela indiscutível necessidade de aceleração desses processos protetivos e reparatórios das consequências sociais da violência, os quais podem implicar problemas no desenvolvimento.

\section{Políticas Públicas Sociais: gênero e violência}

O marco político para a melhoria, qualificação e participação pública social no processo de organização das políticas públicas foi o processo de democratização, que se iniciou numa movimentação social para estabelecer eficácia e efetividade nas ações governamentais, com a descentralização e a participação do cidadão na formulação e implantação das políticas públicas.

Segundo Farah (2001), está associada a essa nova construção a inclusão dos 
atores sociais no processo de elaboração e execução de políticas públicas voltadas para o interesse da sociedade e dos grupos da sociedade civil organizada, somando capacidades que ultrapassam a ação isolada do Estado, para resolução dos conflitos de interesse público, envolvendo a sociedade civil e os cidadãos articulados politicamente para a formulação de políticas públicas.

Embora todo processo necessite de vários atores, para que a política pública venha a contemplar as necessidades do maior grupo populacional, o processo envolve atores racionais, e nem sempre o exercício da racionalidade, mediada por interesses e preferências individuais, conduz a resultados desejados pela coletividade.

A vida democrática expressa o encontro de várias problemáticas que a realidade denota e o Estado pode agir dando respostas efetivas à problemática social, concretizando atos, como a realização de políticas públicas centradas em segmentos populacionais, demandas setoriais, mas, em particular e mais enfaticamente, aos anseios do sujeito sobre o direito do seu próprio desenvolvimento.

A adoção da Declaração Universal dos Direitos Humanos (1948), que foi complementada, em 1966, pelo Pacto dos Direitos Civis e Políticos e pelo Pacto dos Direitos Econômicos e Sociais, marcou as conquistas no enfrentamento das diferenças sociais, compreendendo como direitos humanos os direitos civis, políticos, econômicos, sociais e culturais, e também os direitos dos povos, que servem de modelo ético e normativo para a convivência humana, direcionando leis a serem implementadas visando ao desenvolvimento.

As políticas públicas para as mulheres tornaram-se evidentes com a reafirmação desses conceitos, ações e recursos, com todos os ministérios e seus setores apontando soluções para a problemática da violência contra a mulher.

Para subsidiar o estudo apresentado, detalha-se, a seguir, duas das principais direções estratégicas das políticas públicas para a conjugação de diferentes frentes: a Lei Maria da Penha (BRASIL, 2006) e a Política Nacional de Enfrentamento à Violência contra a Mulher (BRASIL, 2011b).

Em 22 de dezembro de 2006, a Lei no 11.340 passou a vigorar, considerada pela a sociedade brasileira uma resposta à situação de impunidade diante dos crimes sofridos pelas mulheres. A redação dessa lei de punição ao crime de violência doméstica, a Lei Maria da Penha, trata da violência doméstica familiar de gênero com mais rigor. O objetivo da lei é tratar de forma diferenciada a violência doméstica, contendo-a por meio de penas mais severas e tratamento punitivo ao agressor. A Lei Maria da Penha atua em aspectos objetivos e subjetivos: 1) quanto ao aspecto objetivo, coíbe e previne a violência doméstica e familiar contra a mulher, direcionada ao combate dos fatos ocorridos no ambiente doméstico, familiar e intrafamiliar; 2) quanto aos subjetivos, a preocupação é a proteção da mulher contra os atos violentos praticados por homens e mulheres.

Segundo o artigo 70 da Lei no 11.340/2006, as formas de violência doméstica e familiar contra a mulher organizam-se em cinco categorias: "I - a violência física; II - a violência psicológica; III - a violência sexual; IV - a violência patrimonial e a V - a violência moral". Cabe salientar que o detalhamento dos tipos de atos e ações praticados sob cada uma dessas categorias amplia as possibilidades e responsabilidades de 
denúncias, bem como permite inserir no contexto das respostas, por meio de políticas públicas, programas, intervenções sociais qualificadas e as atenções necessárias.

Nesta perspectiva, além da Política Nacional de Enfrentamento à Violência contra as Mulheres (2011b), há também o Pacto Nacional de Enfrentamento da Violência contra as Mulheres (2011a). Este último documento apresenta o conteúdo expresso dos compromissos, prioriedades e as esferas governamentais (federal, estadual e municipal).

Quando um governo estabelece ações em forma de pacto, discute-se conteúdos obrigatórios, ações obrigatórias que, em outros momentos, as políticas públicas não explicitaram por contingências múltiplas. Após a pactuação, tornam-se prioritárias as ações no campo pactuado, que deverão ser executadas com foco em resultados, explicitação dos compromissos, previsão de orçamentos financeiros e as metas a serem obtidas. No Pacto Nacional pelo Enfrentamento à Violência contra as Mulheres (BRASIL, 2011a), considerando a definição de enfrentamento utilizada na Política Nacional de Enfrentamento à Violência contra as Mulheres (BRASIL, 2011b), são estabelecidas políticas amplas e articuladas, que venham dar conta da complexidade da violência de gênero em todas as dimensões.

Para o enfrentamento da violência contra a mulher, o Pacto deve ser efetivado. Para essa efetivação, torna-se necessária a ação conjunta dos diversos setores envolvidos na atenção à mulher, diretamente ou não, quando é imprescindível a intersetorialidade para as ações e discussões. Os setores e políticas públicas envolvidos preliminarmente na efetivação do Pacto de 2011 são: saúde, segurança pública, justiça, educação, assistência social.

O Pacto Nacional de 2011 prevê também que, para o processo de implementação das ações, a criação ou fortalecimento das estruturas das políticas públicas existentes (esferas estadual e municipal), seja estabelecido o Projeto Básico Integral, com diagnóstico, definição de municípios polos, planejamento das ações do Pacto, acordo de cooperação federativa. Além da constituição do comitê gestor e da câmara técnica estadual e municipal de gestão e monitoramento do Pacto, para planejamento, monitoramento e execução de ações.

Nesse sentido, cada ente de uma política pública tem atribuições cujo envolvimento acontecerá por eixos; logo, a estruturação do Pacto pelo Enfrentamento à Violência contra as Mulheres (BRASIL, 2011a) apresenta possibilidade de diretrizes seguras para o enfrentamento das situações de vulnerabilidade e condições de violência, sob orientação dos meios teóricos para a construção de políticas concretas para atendimento às mulheres em situação de violência de forma tripartite, com fluxo de cuidado nas três esferas governamentais, garantindo acesso e cuidado integral às usuárias do sistema.

\section{Resultados e discussões}

Com a pesquisa de campo, foi traçado o perfil mínimo das denunciantes. Há concentração de denúncias de violência sofrida por mulheres em idade entre 21 a 30 anos. Essa constatação corrobora estudos nacionais, os quais identificaram que esse 
é o grupo etário mais vulnerável em relação à violência doméstica.

Associado à faixa etária (mulheres entre 18 aos 60 anos), a pesquisa identificou que a ocupação, a escolaridade e o estado civil das mulheres denunciantes de violência evidenciam a maior vulnerabilidade dessas mulheres. Salientamos ainda que os serviços prestados nos ensinos fundamental, médio e superior podem não estar cumprindo o seu dever na abordagem eficaz das questões de gênero e igualdade de direitos. Isso pode corroborar a ausência de conhecimentos dos direitos, de igualdade de gênero dessas mulheres, o que as faz mais vulneráveis, dependentes dos sistemas para garanti-las.

A baixa escolaridade se soma às condições de pobreza econômica, fator que potencializa um imaginário equivocado: relação natural entre violência, pobreza e economia.

Contudo, as mulheres com maior escolaridade podem ter recorrido a serviços alternativos ou privados de assistência, sem recorrer às denúncias em delegacias. Portanto, os índices levantados podem não corresponder à amplitude da violência contra a mulher no território pesquisado.

Quanto à profissão, as mulheres vítimas de violência que chegaram até as instituições para prestar denúncia, ocupam-se das atividades domésticas, mas as exercidas no âmbito privado do domicílio. Nos BOs, a mulher declara-se como sendo "do lar". Independentemente do grau de escolaridade, é evidente que essas mulheres trabalham sem remuneração (denominadas do lar), condição que as deixa dependentes financeiramente do seu agressor.

\subsection{Ocorrências nos BO das DPs e DPCAMI na 25a ADR}

A violência contra as mulheres faz parte dos demais tipos de infrações denunciadas, que, aos poucos, torna-se visível perante o complexo mundo da violência. Nessa violência direcionada a um recorte populacional, são destacadas certas especificidades nas relações de gênero. Ela está relacionada ao contato íntimo e privado das relações entre homens e mulheres. Quando os episódios de violência se tornam públicos, estes vêm de várias formas, adquirem visibilidade pelos registros nas instituições sociais, como nos serviços de saúde, assistência social, sistema jurídico e sistema de segurança pública.

Somente em Mafra e São Bento do Sul, há delegacias especializadas no atendimento à mulher. Mafra contou primeiramente com o Centro de Proteção à Criança, Adolescente, Mulher e Idoso, criado em março de 2008, passando a ser denominado delegacia somente em abril de 2009. Em São Bento do Sul, já surgiu denominada delegacia, no ato de sua criação, em 2008. Ambas as delegacias trabalham como espaços especializados denominados Delegacias de Proteção à Criança, Adolescente, Mulher e idoso (DPCAMI), nas quais foram coletados os dados deste estudo. Este serviço tornou-se uma via de fácil acesso e tornou visível a violência de gênero na 25a ADR. A criação das delegacias da mulher, além de aumentarem a visibilidade da violência, aumentam a abrangência dos fatos e sua conceituação.

Em 3.769 BOs, o registro principal, ou seja, o fato denunciado é violência con- 
tra a mulher em todas as faixas etárias. Assim, é preciso que sejam recuperadas duas definições: violência doméstica e violência de gênero. Consideramos como violência doméstica a ocorrência em qualquer relação íntima de afeto, na qual o agressor conviva ou tenha convivido com a ofendida, independentemente de coabitação, como descrito na Lei no 11.340 (Lei Maria da Penha); portanto, consideramos violência não doméstica as outras formas de violência contra a mulher.

Assim computamos neste estudo a violência não doméstica, levando em consideração os registros que tinham como autor da violência o sexo masculino e os lugares públicos, ou seja, fora do domicílio. Ressaltamos que estes dados não representam a totalidade da violência contra as mulheres nos municípios estudados. Também afirmamos que há violência que não foi registrada nas DPs e DPCAMI. Reiteramos que se sabe de antemão que o cenário atual da violência doméstica e de gênero não é completamente denunciado, tendo em vista que nem todas as mulheres procuram esses serviços para realizar denúncias, devido às situações que permeiam a violência, como o medo do agressor, a vergonha, a dependência do agressor, entre outras justificativas.

Levantamos nos BOs os dados relacionados à violência, os quais foram computados por ano, em separado (2009 a 2012). Em sequência à seleção, os dados dos municípios selecionados foram sistematizados, para que este estudo desse conta do cenário da violência contra a mulher. Sobre os dados, a respectiva análise evidencia dois cenários da violência contra as mulheres na 25ạ ADR. Há municípios cujos dados mostram um cenário de significativa ascendência nos números de registros, e outro cenário, certo declínio nos casos registrados, ano por ano. Esses dois aspectos podem levar a múltiplas explicações no contexto da violência contra o gênero feminino no território pesquisado.

Observou-se que, entre 2009 e 2012, houve aumento dos registros em BOs. É possível que esse aumento das denúncias se deva às condições que favoreceram tal situação, como, por exemplo, campanhas informativas, instituições específicas, tomada da consciência das vítimas. A problemática da violência contra a mulher vem referenciando os avanços e a elaboração de políticas públicas para o seu enfrentamento e empoderamento da mulher.

A contribuição da sociedade, para a modificação das condições sociais e coletivas na formulação das políticas públicas para a organização do Estado, objetiva enfrentar e punir os atos violentos cometidos contra as populações vulneráveis (crianças, mulheres, idosos). Isso pode ter aumentado a confiabilidade das mulheres na organização social, contribuindo para o aumento das denúncias por parte das vítimas.

Outra situação que pode ter intensificado o número dos registros em BOs é o fato de as políticas públicas sociais terem fortalecido os grupos ditos vulneráveis. As políticas públicas empregadas no cenário brasileiro, para o combate à violência contra a mulher, retiraram a violência contra o sexo feminino do cenário privado e a tornaram "coisa pública".

Entre os marcos sociais e legais que estão sustentando a reação contra a violência, pode ser referenciada a Lei de Internacional de Direitos da Mulher (1979), 
que, embora não tão antiga, visou reprimir formas de discriminação e promover os direitos das mulheres. Com a implantação do Conselho Nacional dos Diretos das MuIheres (1985), também se cria a Delegacia de Defesa das Mulheres e, posteriormente, as delegacias especializadas no atendimento da mulher. Essas delegacias se constituíram nos espaços de atenção às vítimas de violência. A delegacia significaria que aquela violência invisível e sem importância social, finalmente, tornar-se-ia pública e notória. A Medida Provisória no 103, de 2003, e o Decreto no 2.315, de 4 de setembro de 1997, com o objetivo de assegurar a aplicação das legislações anteriores, para a proteção das mulheres vítimas de violência, ou em situação de vulnerabilidade, estabelecem, de forma organizada, as competências de cada agente público.

O II Plano Nacional de Políticas para as Mulheres (BRASIL, 2008) norteou a elaboração da Política Nacional de Enfrentamento à Violência contra as Mulheres, que subsidiou a Lei $n$ o 11340/2006, denominada Maria da Penha, a qual se evidencia como uma das maiores conquistas da sociedade brasileira, pois instituiu medidas punitivas para os agressores. Em 2006, foi criado o Pacto Nacional pelo Enfrentamento à Violência Doméstica contra a Mulher.

Antes disso, a vulnerabilidade, as questões de gênero e a violência contra a mulher são enfrentamentos assegurados a partir das determinações da Constituição Federal do Brasil (BRASIL, 1988), que garantiu a igualdade de direitos entre homens e mulheres. O Plano Nacional de Políticas para as Mulheres (BRASIL, 2004) norteou a elaboração da Política Nacional de Enfrentamento à Violência contra as Mulheres (BRASIL, 2011b) e subsidiou a Lei no 11.340/2006, denominada Maria da Penha (BRASIL, 2006), a qual se evidencia como uma das maiores conquistas da sociedade brasileira, pois instituiu medidas punitivas para os agressores. Em agosto de 2007 foi criado o Pacto Nacional pelo Enfrentamento à Violência Doméstica contra a Mulher (BRASIL, 2011a), o qual tem como um dos seus objetivos a implementação da Lei Maria da Penha e a ampliação da rede de atendimento à mulher.

Diante dessa organização, o contexto histórico das políticas públicas contra a violência ao gênero feminino tem, na Lei no 11340/2006, um marco conceitual sem precedente para o tratamento dos casos de violência contra as mulheres. Tal lei surgiu devido à Lei no 9.099/1995 ser branda em relação à aplicação das penas para o agressor, atribuindo-a por meio de cestas básicas, multa e prestação de serviço comunitário. A lei atualmente em vigência contempla, em seu texto, penalidades para coibir a violência doméstica e familiar contra a mulher.

No contexto de organização da rede de atenção às mulheres e à violência que as torna vítimas, em 1998, o Ministério da Saúde deu prioridade à saúde da mulher, trabalhando três linhas principais de ação para atender, de forma plena, esse segmento do gênero, contemplando as necessidades de atenção qualificada às mulheres brasileiras. Para tanto, a terceira linha de ação refere-se justamente à participação da saúde, para dar conta da violência contra a mulher, qualificando o atendimento às vítimas de violência, de forma articulada com outros setores envolvidos: assistência social, educação, justiça, segurança pública, entre outros, na atenção às mulheres. 
A influência da organização da rede de atenção às mulheres, por meio do amparo legal das políticas públicas sociais, pode explicar dados que expõem um aumento maior de casos registrados nos BOs, o que se dá de forma significativa entre os anos de 2009 a 2012. Tal influência pode ser observada em São Bento do Sul, que, entre os sete municípios pesquisados, é o único com rede estruturada em conformidade com o disposto nas políticas públicas de amparo às mulheres vítimas de violência. Alertamos que essa rede de atenção é composta por delegacia especializada (DPCAMI), Centro de Referência da Assistência Social (CRAS), Centro de Referência Especializado da Assistência Social (CREAS), Casa Abrigo, unidades de urgência e emergência, Instituto Médico Legal e Conselho Municipal da Mulher, o que nos permite pressupor que a mulher tem múltiplas possibilidades de recorrer aos serviços estruturados para atendê-la de forma humanizada e acolhedora, com segurança para apoiar e efetuar as denúncias.

Mas, mesmo assim, o cenário formado após a pesquisa de campo instiga uma hipótese relacionada a possíveis fragilidades do sistema de atenção às mulheres vítimas de violência. Faz-se necessário mencionar tais fragilidades. A rede de atenção à mulher encontra-se fragmentada, ainda que devesse estar articulada com os serviços previstos pelo MS, em 1998, pelo Pacto de enfrentamento à violência contra a mulher, em 2007. Segundo Política Nacional de Enfrentamento à Violência contra as Mulheres (BRASIL, 2011b), o conceito de rede de atendimento refere-se à atuação articulada entre as instituições, os serviços governamentais, não governamentais e a comunidade. Se a rede estivesse articulada, trabalharia questões relacionadas à ampliação dos serviços com qualidade e agilidade na identificação e encaminhamento dos casos, efetivando as ações de prevenção na comunidade. A rede segue uma organização multidisciplinar entre as várias esferas: saúde, educação, justiça e segurança pública, atuando na complexidade da violência contra as mulheres. O que se pôde observar nos municípios em que houve redução nas denúncias é que ainda há falta de organização da rede de atendimento, pois ainda não se contemplou o que preconizam as políticas públicas.

Também podemos destacar uma indagação quanto à organização dos horários de atendimento das instituições públicas para acolher as mulheres vítimas de violência. Todas as delegacias visitadas trabalham de forma padronizada, atendendo no período da manhã e durante a tarde. Não há atendimento de porta aberta durante a noite e nos finais de semana. Essa situação pode contribuir para que a mulher não registre o BO posteriormente à violência sofrida, pois, dependendo do tempo em que ocorreu a violência, cessa o sentimento de dor, dando ênfase ao sentimento de medo e dependência emocional da mulher vítima de violência para o com seu agressor. Segundo Nascimento (2004), a subordinação, opressão, discriminação da mulher não é própria do gênero, mas está relacionada às formas de convívio, à dominação mantida pelas sociedades, legitimando o controle do homem sobre as mulheres.

Tais situações citadas podem estar também vinculadas à dependência financeira dessas mulheres para com seus agressores. Foi observado, neste estudo, que a maioria das mulheres denunciantes não exercem trabalho remunerado, o que pode, 
de algum modo, ser relacionado aos atos violentos. A violência contra as mulheres é influenciada por fatores vinculados à comunidade, tal como pobreza, baixa posição socioeconômica, desemprego, associação com companheiros delinquentes, isolamento da mulher e da família. Quando destacamos as relações pessoais, podemos observar os conflitos conjugais, o controle que o parceiro exerce sobre o patrimônio familiar e a não participação da mulher na tomada de decisões em relação às situações familiares, hegemonia masculina na gestão familiar.

\subsection{Cenários da violência contra a mulher na 25a ADR}

O grupo de dados apresentados a seguir foi identificado nos BOs das delegacias - espaço do formulário que descrevia o fato comunicado. Cada indicação no BO foi registrada no campo específico, cujo roteiro foi sistematizado, seguindo a descrição dos tipos de violência da Lei no 11.340/2006 (Lei Maria da Penha). A violência sofrida e registrada não se apresenta de forma isolada, mas associada a outras formas de violência, já que uma mesma mulher pode sofrer, ao mesmo tempo, violência física, psicológica, moral, patrimonial e sexual.

A violência tende a crescer. Pode iniciar com agressões verbais, passando para as físicas, psicológicas e sexuais, podendo culminar em homicídio. A violência que aparece predominantemente na sequência da classificação das violências indicadas neste estudo é a violência psicológica, registrada pelo termo ameaça. Ademais, o ponto forte da violência psicológica causa danos invisíveis à mulher. Essa forma de violência registra a recuperação mais difícil (da mulher), requerendo apoio técnico e profissional.

A denúncia a essa forma de violência, antes tida como inofensiva e naturalizada nas relações sociais e humanas, pode ter sido estimulada pelo amparo legal da Lei Maria da Penha, que define e subsidia o julgamento da violência moral e psicológica, indicação evidenciada pelo número de denúncias realizadas nos anos estudados, percebida pelo possível reconhecimento das mulheres sobre o que é violência e quando esta se percebe como sendo agredida.

Para dar conta das manifestações da natureza da violência psicológica, a Secretaria de Vigilância em Saúde (MONTEIRO, 2005) pontua exemplos rotineiros na violência contra a mulher: quando esta é impedida de trabalhar, sofre manipulação financeira, não recebe apoio para a educação dos filhos, como também enfrenta ameaças constantes ou espancamento ou morte.

Nesse cenário, podemos considerar a influência das condições sociais e históricas predominantes; logo, a violência é um fenômeno social. A violência física desperta sentimentos de raiva e impotência nas mulheres, que reforça o ciclo da violência. Além das marcas deixadas no corpo da mulher, a violência física provoca outras formas de violência que não são percebidas no momento da agressão, e, sim, tendem a apresentar-se posteriormente, manifestando-se em doenças orgânicas e emocionais, sentimento de culpa, baixa estima, estado de depressão, mantendo a mulher isolada e desestimulada a lutar para livrar-se das manifestações de violência física. A justificativa reside no fato de que este crime apresenta nuances diferencia- 
das, inerentes à sua prática, devendo ser analisado de forma específica.

Observamos nos dados coletados a presença predominante da violência física, a qual pode estar associada a outras formas de violência. A violência pode evoluir para agressão física. As denúncias registraram que a agressão física foi por tapas, socos, empurrões, pontapés, desferidos por homem com vínculo familiar com a vítima. Observa-se pelos dados que os homens autores das agressões denunciadas vivem ou já viveram uma relação conjugal, nem sempre legalizada, com a vítima. Os autores da violência geralmente são os maridos, ex-maridos e namorados. Porém uma situação preocupante na violência doméstica é a indicação da agressão realizada pelos filhos. Isso mostra que até mesmo as relações de consanguinidade com a vítima não impedem a prática de violência geracional.

A violência cometida no âmbito familiar recobre o universo das pessoas relacionadas por laços consanguíneos ou afins. Essa forma de violência (doméstica) deixa marcas profundas na vida dessas mulheres, embora os atos violentos não estejam estampados no corpo das vítimas, mas provocam traumas profundos. A violência doméstica expressa a magnitude das relações de poder ainda existentes na sociedade, que sempre naturalizou a violência intrafamiliar.

A violência doméstica incide diretamente sobre a vida da mulher. Uma prova dessa afirmação está no histórico da criação da Lei Maria da Penha (2006), devido à fragilidade do serviço de segurança pública para adentrar o íntimo familiar e julgar a violência doméstica como crime. Portanto, a criação de um dispositivo jurídico para coibir exclusivamente a violência doméstica evidencia a gravidade da questão.

No terceiro conjunto de dados coletados nos BOs, que caracterizam os atos violentos contra as mulheres, no espaço da 25a ADR, a violência física é destacada pelas marcas deixadas no corpo da vítima, para que ela perceba a relação de poder que o agressor tem sobre o seu corpo, mantendo o ciclo da violência.

\section{Considerações finais}

Na constituição das redes de atenção e cuidados para o enfrentamento das violências contra as mulheres, os serviços não são somente aqueles especializados. Embora os órgãos da Rede de Atendimento às mulheres em situação de violência, estejam estruturados com poucos componentes especializados, as mulheres procuram estes serviços para efetuarem as denúncias de violência sofridas. Porém, o que foi evidenciado foi a fragilidade no encaminhamento, nos fluxos, na assistência prestada às mulheres vítimas de violência. Este processo ocorre de forma fragmentada, levando as mulheres percorram o mesmo círculo várias vezes.

Com base no aporte teórico das políticas públicas pôde-se avaliar que após 25 anos de estruturação na linha de atenção às mulheres vítimas de violência, as várias legislações e estratégias na prática, são incipientes. Se há recursos financeiros federais disponíveis para o atendimento das violências contra as mulheres, por que estes não são aplicados o território estudado conforme os preceitos da Política e do Pacto Nacional?

Diante do crítico cenário da violência contra as mulheres, é imperioso que a 
execução das políticas públicas contribua para a diminuição das disparidades locais. Desse modo pontuaram-se questões suscitadas dos dados e reflexões sobre o território estudado, as quais têm, podem e devem contemplar a presença ativa dos entes institucionais mencionados nas legislações e políticas públicas.

Discussão do tema com os gestores locais e das instituições privadas e públicas que fazem parte da rede de serviços de atenção às mulheres vítimas de violência, em especial de saúde, educação, segurança pública, justiça e assistência social, comprometidos pelo Pacto Nacional reconhecem a dimensão da problemática, pelo cenário das violências evidenciado neste estudo. O comprometimento deverá ser evidenciado na execução das políticas públicas superando a fragmentação e intensificando-se o principal entrave das políticas públicas: ausência ou frágil intersetorialidade.

- Discussão permanente entre os profissionais que obrigatoriamente compõe a rede de atenção e cuidados, para o enfrentamento das violências contra as mulheres.

- Continuidade de pesquisas para a identificação e aprofundamento da identificação das vulnerabilidades sociais existentes nos territórios de concentração dos atos violentos e sobre eles acelerar a implementação e execução das políticas públicas.

- Proposição de estratégias de empoderamento das mulheres, tanto as que vivem em situação de violência como também as profissionais que prestam assistência e atendimento neste setor das problemáticas humanas.

- Elaboração de cartilha educativa que possa ser utilizada pelos distintos atores e entes institucionais, a serem utilizadas em oficinas, eventos, serviços, distribuídos em escolas, setores de saúde e da assistência social, bem como para a formação de capital humano e social.

O estudo sobre o cenário da violência contra a mulher, aplicado no espaço da 25a ADR, é resultado da trajetória que percorremos, na qual realizamos descobertas jamais imaginadas. Viajamos por um mundo cheio de revelações que provocaram o anseio de entender os pormenores deste cenário.

O estudo colaborou para o entendimento das circunstâncias que permeiam a vida das mulheres vítimas de violência. Também aguçou nossa curiosidade para entender o porquê da permanência do ciclo social da violência, apesar de tantos meios ou estratégias para contê-lo.

A violência vivenciada por essas mulheres no cenário estudado assume múltiplas matizes, e observamos que a permanência dessas mulheres nesse contexto de violência é frequentemente agravada pelas formas de violência inferidas contra o seu reduto (corpo), ou seja, sofrendo agressões física, moral ou psicologia, que, no estudo, apareceram com menos evidência, porém deixam marcas em consequência da violação dos seus direitos humanos, marcada pela exclusão social a que são submetidas.

A violência está presente nas relações interpessoais, afetando diretamente as condições de vida das mulheres. O ciclo da violência doméstica perfaz toda a rotina de vida diária dessas mulheres; uma vez iniciada a ruptura, torna-se um processo difícil, devido à dinâmica familiar e nem sempre o apoio e a segurança necessários 
para atender a esse segmento.

Esta condição de sofrimento para essas mulheres é antecipada por uma rotina marcada por desentendimentos, relações conturbadas por ciúmes, agressões constantes, praticadas pelo agressor após ter ingerido álcool ou drogas. Também pelo perfil agressivo do companheiro ou agressor, a situação da mulher vítima de violência permanece em uma constante alternância entre cenas de violência e visitas às instituições especializadas ou com atribuições para atendê-la. A condição da violência contra as mulheres está interligada às questões de vulnerabilidade social. Nos municípios estudados, pelo perfil das mulheres e pelos fatores que favorecem a violência, fica evidente que elas pertencem a um recorte populacional de clara presença da vulnerabilidade.

Seguindo o propósito deste estudo, buscamos interpretar como esse cenário aparece e transparece no e para o desenvolvimento regional. Entre tantos meandros, ao analisamos o processo das políticas públicas sociais que apoiam o enfrentamento da violência contra as mulheres, após a Constituição Federal do Brasil de 1988, estudamos as políticas sociais pelas quais um segmento, um grupo, uma comunidade, um local e uma região podem ser estimulados a buscar o bem-estar, a paz, a justiça social, a igualdade e a equidade.

Com o passar dos anos, o desenvolvimento é um pensamento, uma ação mediada pelos enfrentamentos, para que a sociedade atue de forma incisiva sobre suas questões. Neste complexo de enfrentamento, a violência e o seu direcionamento à mulher evidenciam-se como um custo social significativo pelas suas consequências. Além dos traumas individuais, a segurança e as referências dos sujeitos e dos grupos familiares são ameaçadas e se tornam vulneráveis.

Desenvolvimento, crescimento, mudanças e transformações são processos inerentes à vida humana e social; portanto, as políticas públicas, que se tornam instrumentos dos enfrentamentos dos dilemas humanos e sociais, tornam-se recursos relevantes nos espaços individuais e coletivos. A região na qual se age e interage evidencia um movimento que pode promover o desenvolvimento.

Portanto, entre tantos dilemas e enfrentamentos, os mecanismos de proteção à mulher, os marcos legais que demarcam essa ênfase no tratamento da questão (por exemplo, a Lei Maria da Penha) evidenciam a intolerância sobre a violência contra as mulheres. Devemos destacar que uma lei não contempla de modo efetivo todas as nuances de uma questão tão complexa como a relativa à violência, por isso, um ponto relevante nesse processo decorre da força política advinda do respaldo legal das políticas públicas, que se podem transformar efetivamente no desenvolvimento de uma rede de serviços para a atenção das mulheres que foram vítimas e denunciam a violência nos municípios da 25a ADR. O aporte teórico que as políticas públicas oferecem permite avaliar este item, deixando claro que, após 25 anos de estruturação na linha de atenção às mulheres vítimas de violência, encontramos várias legislações e estratégias organizadas, mas que, na prática, ainda são incipientes.

Também há recursos financeiros federais disponíveis para o tratamento da violência contra as mulheres. Por isso, questionamo-nos por que esses mecanismos não estão sendo implantados na região estudada? 
Salientamos que o município no qual a rede encontra-se mais estruturada alcançou índices maiores no crescimento das denúncias. Essa situação nos dá duas possibilidades de explicação: há mais violência neste município, ou a rede está assegurando maior confiabilidade para as denúncias. Isso denota que, no desenvolvimento regional, o local é importante e pode sustentar os processos mais abrangentes.

Ainda pode estar havendo subnotificação nos outros municípios, pois, quando a mulher é estimulada pelos mecanismos a falar sobre a violência que sofreu e não tem apoio da rede, ela fica fragilizada e intimidada para efetuar a denúncia.

Diante do cenário pesquisado, os dados nos levam a apontar para uma imprescindível reflexão sobre o termo desenvolvimento. Na discussão do contexto da violência contra as mulheres, apontaríamos que, na redução dos índices que revelam essa problemática, o desenvolvimento não contempla o humano, o social, o local, o regional. Há questões do cumprimento das políticas públicas que estão negligenciados e interferem no processo do desenvolvimento, pois consomem recursos, não dão suporte à inclusão social e perpetuam o problema.

Entendemos que o desenvolvimento humano se dá por meio do caminhar contínuo, não determinado por processos biológicos e genéticos, mas pelo desenvolvimento socioeconômico. Este é mais amplo e é determinado pela cultura, pelas relações sociais, pelo acesso a todos os bens socialmente construídos, pelo consenso de que todos são iguais perante a lei e perante os direitos.

Por outro lado, o desenvolvimento social vai ao encontro do paradoxo que define a nova face da sociedade atual, que é permeada pelas diferenças, conforme a localização ou delimitação geográfica e cultural, as quais influenciam as políticas públicas, as condições socioeconômicas que os sujeitos compartilham, coabitando um espaço interinfluenciado.

A soma dos desenvolvimentos acontece num local, por isso, o cenário territorial se apresenta como desafio frente às disparidades e desigualdades sociais. Temas como políticas públicas locais, sustentabilidade e responsabilidade social estão cada vez mais difundidos nos debates, em práticas que objetivam a sustentabilidade perante ações efetivas e políticas públicas.

Diante do crítico cenário da violência contra as mulheres e do desenvolvimento necessário, é imperioso que os aspectos primordiais, para que as iniciativas e políticas realizadas contribuam realmente na diminuição das disparidades locais, sejam respeitados. É a própria consciência dos fatores que resultaram em tais situações de não desenvolvimento. Isso implica na conscientização, na elaboração e aplicação de processos políticos para reduzirmos os fatores que contribuem para que não alcancemos o desenvolvimento local esperado, uma vez que a violência retira dos sujeitos de uma sociedade a livre circulação e o senso de pertencimento, acuados pelo medo.

Desse modo, podemos também sugerir estratégias para empoderar as mulheres, tanto as que vivem em situação de violência como também as profissionais que Ihes prestam assistência. Assim, podemos sugerir como estratégia para o enfrentamento da violência contra as mulheres no espaço estudado, a elaboração de cartilha educativa, para serem trabalhadas em oficinas para as mulheres, com temas relacionados à violência contra a mulher, despertando no grupo a origem dessa violência, 
as nuances que a permeiam e as formas de enfrentamento, utilizando como método a educação e o conhecimento para ultrapassarmos tais desafios. No entanto, isso só será possível com o engajamento e o comprometimento de todos os atores envolvidos na efetivação desse trabalho, especialmente da participação popular, que, nesse ponto, é vista como pertinente para garantir a integralidade do corpo feminino.

Pontuação final: devemos observar que não basta existirem políticas públicas sociais estruturadas se não estiverem amparadas pela responsabilidade política dos gestores públicos e privados e dos profissionais responsáveis em implementá-las.

\section{Referências}

ALBERDI, I. et al. Cómo reconocer y cómo erradicar la violencia contra las mujeres. In: Violencia: Tolerancia Cero. Programa de prevención de la Obra Social "la Caixa". Barcelona: Fundación La Caixa, 2002.

BRASIL. Constituição da República Federativa do Brasil. Promulgada em 5 de outubro de 1988.

. Secretaria Especial de Políticas para as Mulheres (SPM). Pacto Nacional pelo Enfrentamento à Violência contra as Mulheres. Brasília, 2011 a.

Mulheres. Brasília, $2011 \mathrm{~b}$.

. Política Nacional de Enfrentamento à Violência contra as . Il Plano Nacional de Políticas para as Mulheres. Brasília, 2008.

. Plano Nacional de Políticas para as Mulheres. Brasília, 2004.

. Supremo Tribunal de Justiça. Lei no 11.340/2006, Lei Maria da Penha, 7 de agosto de 2006. Disponível em: <http://www.stj.sjs.br/...IA\%20LEI\%MARIA\%20 DA\%20PENHA\%20revisado>. Acesso em: 15 dez. 2011.

FARAH, Marta Ferreira dos Santos. Parcerias, novos arranjos institucionais e políticas públicas no nível local de governo. Rio de Janeiro: Revista de Administração Pública, 2001.

MINAYO, M. C. S.; SOUZA, E. R. (Orgs.). É possível prevenir a violência? Ciência \& Saúde Coletiva, Rio de Janeiro: 1999.

(Orgs.). Violência sob o olhar da saúde: a infra política da contemporaneidade brasileira. Rio de Janeiro: Fiocruz, 2006.

MONTEIRO C. F. Marcas no corpo e na alma de mulheres que vivenciam a violência conjugal: uma compreensão pela Enfermagem. Rio de Janeiro: Escola de Enfermagem Anna Nery/UFRJ, 2005.

MORGADO, Rosana. Mulheres em situação de violência doméstica. In: GONÇALVES, H. S.; BRANDÃO, E. P. (Orgs.) Psicologia Jurídica no Brasil. 2. ed. Rio de Janeiro: NAU, 2008.

NASCIMENTO, M. L. Violência doméstica e sexual contra as mulheres. Psiqweb. Disponível em: <http://www.elacso.org>. Acesso em: 10 nov. 2004. 
OPAS. Organização Panamericana da Saúde. Violência y salud. Washington, 2007.

SAFFIOTTI, Heleieth lara Bongiovani. Gênero, patriarcado, violência. São Paulo:

Perseu Abrano, 2004.

SUÁREZ, Mireya; BANDEIRA, Lourdes (Orgs.). Violência, gênero e crime no Distrito Federal. Brasília: UNB, 2002. 